\title{
TESTING ACCURACY OF BUTT LOG VOLUME ESTIMATED BY USING SEVEN FORMULAS FOR CALIBRAIN PINE ( Pinus brutia Ten )
}

\author{
Mohammed H. Obeyed \\ School of Forestry / Faculty of Agriculture \& Forestry / Dohuk Univ., Iraq \\ E-mail: moh_forest@yahoo.com
}

\begin{abstract}
The observed volumes obtained by several volume calculation methods for the butt log volume of Calibrain pine (Pinus brutia Ten.). These butt logs were compared with true volume of each butt log which was determined by aggregating the volumes of measured short $(1 \mathrm{~m})$ using Smalian's formula. 150 of sample trees were measured into Zaweta and Atrush districts of Dohuk province. The sample trees presented diameter at breast height from 13.9 to $37.6 \mathrm{~cm}$. and total height from $8-19.2$ meter. The volume of each butt log was estimated by using (Smalian's, Huber's, Newton's, Hossfeld's, Bruce's, Sorenson's and Centroid method). The accuracy of these seven procedures was analyzed considering volume of butt log lengths 6-m. The results showed that Centroid method was superior for all volumes. As expected, Sorenson formula was the procedure with the worst performance.

Keywords: Butt log volume, Centroid method, Individual tree volume, Log volume, Stem volume formula.
\end{abstract}

Received: 6/7/2011, Accepted: 24/6/2013.

\section{INTRODUCTION}

Numerous equations are available to estimate log volume Avery and Burkhart (2002). Some of the most common equations are: Smalian, Huber, Newton, Bruce's, Hossfeld's and the Centroid method. More recently, the Centroid method was developed by Wiant et al. (1992) which is similar to the Newton formula but utilizes cross-sectional area at the midvolume point rather than at midlength. All equations are fairly accurate Patterson et al. (1993), fund that Huber's equation, which uses only the midlength cross-sectional area, ignored the butt swell and underestimated the volume by approximately 6 percent. Newton's equation, which uses a weighted average of the midlength, small end and large end cross-sectional area, overestimated the volume by nearly 11 percent for $5 \mathrm{~m}$ length $\log$. Smalian's equation, which uses the crosssectional areas of the ends, overestimated the volume by 38 percent for $5 \mathrm{~m}$ length $\log$.

Bruce (1982) derived a formula using only end diameters and length that was popular in the western United States. In a study by Yavuz, (1999) for the second 6meter softwood logs of 21 logs of Ash (Fraxinus angustifolia subsp. oxycarpa), 38 logs of Spruce (Picea orientalis (L.) Link.), and 33 logs of Beech (Fagus orientalis Lipsky.) volumes calculated by Newton's, Smalian's, Huber's, Hossfeld's and Centroid formulas were compared with true volumes of each log which was determined by aggregating the volumes of measured short sections $(1 \mathrm{~m}$.) using Smalian's formula, Centroid's and Hossfeld's method produced the least biased result, and the mean errors of the other standard estimates (Huber's, Smalian's, and Newton method) were significant at 0.05 probability level for all species. It should now be 
apparent that in calculating cubic volume of trees and logs, mensurationists should select their methods carefully.

In Iraq, Smalian, Huber and Newton formulae are most commonly employed for estimating log volumes, but it is the first attempt to apply each of equations (Hosfield, Bruce, Sorenson's, and Centroid method ) to calculating butt log volume at $6 \mathrm{~m}$ length $\log$, and then compared with other conventional methods or classic methods (Smalian, Huber, and Newton) formulas in calculating stem volume.

There were three objectives for this study:

1. Introduce various methods used to estimate butt log volume at $6 \mathrm{~m}$ length.

2. Comparison between these equations to choose which one is better for calculating butt log volume at $6 \mathrm{~m}$ length log and with high accuracy instead of calculating the stem volume at $1 \mathrm{~m}$ or $2 \mathrm{~m}$.

3. Reducing drastically the costs, time consuming and sampling effort.

\section{MATERIALS AND METHODS}

The suitability of the volume equations were examined with data from two natural forests of pine trees, data came from temporary plots laid out in Atrosh and Zaweta districts. A total of 150 trees have been measured. Diameter at breast height ranged from $13.9-37.6 \mathrm{~cm}$, total height from $8-19.2$ meter. Before taking any measurement, approximately 75 sample trees were selected from the interior of each district. Trees possessing multiple stems, broken tops, obvious cankers or crooked boles were not included in the sample. Tree measurements included stump diameter outside bark (height from ground, $\mathrm{d}_{0.3}$ ), and diameter outside bark at breast height $\left(\mathrm{d}_{1.3}\right)$, and all diameters outside bark at one-meter height interval above breast height $\left(\mathrm{d}_{2.3}, \mathrm{~d}_{3.3}, \mathrm{~d}_{4.3}, \mathrm{~d}_{5.3}\right.$ and $\left.\mathrm{d}_{6.3}\right)$, diameter inside bark at $\left(\mathrm{d}_{6.3}\right)$ was measured by using Bark Gauge instrument to estimate bark thickness at $\left(\mathrm{d}_{6.3}\right)$, then measuring diameter inside bark by the following formula:

$$
d_{i b}=d_{o b}-2 b_{t}
$$

Where:

$\mathrm{d}_{\mathrm{ib}}=$ diameter inside bark.

$\mathrm{d}_{\mathrm{ob}}=$ diameter outside bark.

$b_{t}=$ Bark thickness.

All diameters measured by caliper P.W. West. (2009) via two measures taken of diameter at right angles to one another and use the average. Total height $(\mathrm{H})$ of the sampled trees measured by Haga Altimeter. (Husch B. 2003).To obtain a "true" volume or control volumes of each butt log, diameter outside bark was measured with caliper at one meter Intervals along the length of each log, the volume of each small section was estimated by using Smalian's equation and summed Ozcelik et al (2010). Butt log volumes were calculated for 6 meter log length above the stump by using several equations. Then they were compared to the corresponding accumulated volumes of 1-meter sections calculated by using Smalian's formula, the assumed true volume. 
Butt log volumes can be determined quite accurately by using testing of good formulas. However, there is still a need to estimate log volumes in the field for research as well as industry applications. Seven equations were used to calculate the volume of butt logs that include:

\section{Smalian's Formula}

Smalian's formula uses cross sectional area at the large end of the $\log (\mathrm{B})$ and at the small end of the $\log (\mathrm{S})$, and log length $(\mathrm{L})$ to estimate $\log$ volume:

Smalian: $\mathrm{V}=((\mathrm{B}+\mathrm{S}) / 2)$

Smalian's equation is fairly accurate for upper logs, but tends to greatly overestimate the volume of butt logs Wiant et al (1996).

\section{Huber's Formula}

The cubic volume was calculated from the measurement of the length of the log and a single diameter measurement on the outside of the bark (dob) from the middle of the log. Huber's formula for estimating the cubic volume is as follows:

Huber: $\mathrm{V}=\mathrm{ML}$

\section{Newton's Formula}

Newton's formula is considered more exact than Smalian's and Huber's formula Husch B. (2003) but it requires measurement of diameter at the small end (S), midpoint (M), and large end (B) of a log, it is more time consuming and suffers from the same impracticality as the Huber formula.

Newton: $V=((B+4 M+S) / 6) L$

\section{Hossfeld's Formula}

This cubic volume formula requires the measurement of two diameters; one at the small end of the $\log (\mathrm{S})$ and one at a point two-thirds of the log. On logs, it gives more accurate results than either the Smalian or the Huber Formula but the measurement of diameter at the two-thirds point is somewhat of a disadvantage.

$$
\text { Hossfeld's: } \mathrm{V}=((3 \mathrm{G}+\mathrm{S}) / 4) \mathrm{L}
$$

\section{Bruce's Formula}

Bruce (1982) derived a formula using only end diameters and length that were popular in the western United States. Bruce's formula performed better than Smalian's formula and is recommended for use when only the ends of logs are accessible for measuring diameter.

$$
\text { Bruce: } \mathrm{V}=(0.25 \mathrm{~B}+0.75 \mathrm{~S}) \mathrm{L}
$$

\section{Sorenson's Formula}

Sorenson's formula is derived from the Huber formula by assuming taper of 1 centimeter per 1.2 meter of log length. This assumption allows measurement of log 
diameter inside bark at the small end. Its accuracy depends on the validity of the taper assumption.

Sorenson: $\mathrm{V}=(\hat{S}+0.05 \mathrm{~L})^{2} \mathrm{~L}$

\section{Centroid Formula}

Centroid method is more recent formula used in this research to estimate butt log volume at $6 \mathrm{~m}$ length, developed by Wood et al. (1992), which is similar to the Newton formula but utilizes cross-sectional area at the midvolume point rather than at midlength.

Centroid: $\mathrm{V}=\mathrm{SL}+(1 / 2) \mathrm{b}_{1} \mathrm{~L}^{2}+(1 / 3) \mathrm{b}_{2} \mathrm{~L}^{3}$

In the Centroid method Wood and Wiant (1990), the log volume is estimated by three steps.

First step: diameter at large $\left(\mathrm{d}_{0}\right)$ and small $\left(\mathrm{d}_{\mathrm{n}}\right)$ ends of the log, and the log length (L) are measured.

Second step: the Centroid distance (q) from the large end of the log was calculated as follows:

$q=L-\left(\frac{\left(\frac{d o}{d n}\right)^{2}-\sqrt{2}}{\sqrt{2}\left(\frac{d o}{d n}\right)^{2}-\sqrt{2}}\right) L \quad \ldots \ldots \ldots \ldots . . .(8)$ And at this point the Centroid diameter (dc) was measured.

Third step: the parameters $\left(b_{1}\right.$ and $\left.b_{2}\right)$ of the Centroid Volume Equation (7) are estimated by Equation (9) and (10).

$$
\begin{aligned}
& \mathrm{b}_{1}=\left(\mathrm{B}-\mathrm{S}-\mathrm{b}_{2} \mathrm{~L}^{2}\right) / \mathrm{L} \ldots \ldots \ldots \ldots \ldots \ldots \ldots \ldots \ldots \\
& \mathrm{b}_{2}=(\mathrm{B}-\mathrm{C}(\mathrm{L} / \mathrm{e})-\mathrm{S}(1-\mathrm{L} / \mathrm{e})) /\left(\mathrm{L}^{2}-\mathrm{Le}\right)
\end{aligned}
$$

Where:

$\mathrm{B}=$ Cross-sectional area at large end of butt log outside bark $\left(\mathrm{m}^{2}\right)$.

$\mathrm{G}=$ Cross-sectional area at $1 / 3$ of butt log length from the large end of the butt log outside bark $\left(\mathrm{m}^{2}\right)$.

$\mathrm{M}=$ Cross-sectional area at mid-length of butt log outside bark $\left(\mathrm{m}^{2}\right)$.

$\mathrm{S}=$ Cross-sectional area at small end of butt log outside bark $\left(\mathrm{m}^{2}\right)$.

$\hat{S}=$ Cross-sectional area at small end of butt log inside bark $\left(\mathrm{m}^{2}\right)$.

$\mathrm{L}=$ long length (m.)

$\mathrm{C}=$ Cross-sectional area at mid volume of butt $\log \left(\mathrm{m}^{2}\right)$ measured at a distance $\mathrm{q}$ from the large end of butt log outside bark.

$\mathrm{e}=\mathrm{L}-\mathrm{q}$

$\mathrm{d}_{0}, \mathrm{~d}_{\mathrm{n}}=$ diameter $(\mathrm{cm})$ at large and small end of butt log outside bark, respectively.

\section{Analysis:}

Three statistical measures were used for a comparison between the equations in terms of accuracy and choose the best mathematical model based estimate butt log volume. The data were processed on using the programs Statgraphics plus: 4, Minitab and Microsoft Excel 2007. For selecting best-fit formula we used three criteria as follows: 


\section{1- Bias:}

Bias was calculated as the mean of the differences between the measured and the estimated butt log volume. Bias equation is as follow:

Bias $=\sum_{i=1}^{n}(y i-\hat{y} i) / n$

Where $y i=$ observed butt log volume, and $\hat{y} i=$ predicted butt log volume. The closer this value to zero increases the accuracy of the equation.

\section{2- Mean Absolute Percent Errors (MAPE):}

The mean absolute percentage error, known as mean absolute percentage deviation (MAPD), is a measure of accuracy of a method for constructing fitted time series values in statistics Rayer, S. (2007). It usually expresses accuracy as a percentage, and is defined by the formula:

$M A P E=\frac{100 \%}{n} \sum\left|\frac{y i-\hat{y} i}{y i}\right|$

Where $y i=$ observed butt $\log$ volume, $\hat{y} i=$ predicted butt log volume and $n$ number of butt log. The difference between $y i$ and $\hat{y} i$ is divided by the actual value $y i$ again.

\section{3- T- test (Two Sample t-Test):}

The t-test is one type of inferential statistics. It is used to determine if there is a significant difference between the means of two groups. After we collect data we calculate a test statistic with a formula. We compare our test statistic with a critical value found on a table to see if our results fall within the acceptable level of probability.

\section{Compute the $t$-statistic.}

$$
t=\frac{\text { Difference between means }}{\frac{\text { Variance }}{\text { Sample size }}}=\frac{\bar{X}_{1}-\bar{X}_{2}}{\sqrt{\frac{S_{1}^{2}}{n_{1}}+\frac{S_{2}^{2}}{n_{2}}}}
$$

Where:

$\bar{X}_{1}=$ mean of sample 1

$\bar{X}_{2}=$ mean of sample 2

$S_{1}^{2}=$ variance of sample $1=\frac{\sum\left(X_{1}-\bar{X}_{1}\right)^{2}}{n_{1}}$

$S_{2}^{2}=$ variance of sample $2=\frac{\sum\left(X_{2}-\bar{X}_{2}\right)^{2}}{n_{2}}$

$n_{1}=$ number of subjects in sample 1

$n_{2}=$ number of subjects in sample 2 
The t-value will be positive if the first mean be larger than the second and negative if it is smaller.

\section{RESULTS AND DISCUSSION}

Descriptive statistics is the term given to the analysis of data that helps to describe, however, allows us to present the data in a more meaningful way which allows simpler interpretation of the data. The descriptive statistics of stump diameter $\left(\mathrm{d}_{0.3}\right)$, diameter at breast height $\left(\mathrm{d}_{1.3}\right)$, total tree height $(\mathrm{H})$ and all diameters at onemeter height intervals above breast height of the sampled trees $\left(\mathrm{d}_{2.3}, \mathrm{~d}_{3.3}, \mathrm{~d}_{4.3}, \mathrm{~d}_{5.3}\right.$, and $\mathrm{d}_{6.3}$ ), are given in Table (1).

Table (1): Descriptive statistics of pine trees diameters and total height.

\begin{tabular}{|c|c|c|c|c|}
\hline Variable & Max. & Mean & Min. & Variance \\
\hline $\mathrm{d}_{0.3}$ & 41.4 & 16.7 & 25.7 & 31.32 \\
\hline $\mathrm{d}_{1.3}$ & 37.6 & 13.9 & 21.8 & 27.28 \\
\hline $\mathrm{d}_{2.3}$ & 34.5 & 11.8 & 19.3 & 25.96 \\
\hline $\mathrm{d}_{3.3}$ & 32.6 & 10 & 17.5 & 24.53 \\
\hline $\mathrm{d}_{4.3}$ & 32 & 8 & 15.7 & 25.09 \\
\hline $\mathrm{d}_{5.3}$ & 30.2 & 6.2 & 13.6 & 24.10 \\
\hline $\mathrm{d}_{6.3}$ & 28.4 & 4.5 & 11.6 & 23.28 \\
\hline $\mathrm{H}$ & 19.2 & 8 & 11 & 6.69 \\
\hline
\end{tabular}

In this study seven different modeling methods had used in order to estimate butt $\log$ volume at 6-m length above stump of pine tree in Dohuk province (Kurdistan region of Iraq) representing: (a) Smalian's, (b) Huber's, (c) Newton's, (d) Hossfeld's, (e) Bruce's, (f) Sorenson's and (g) Centroid method. All different methods could be used for estimating butt log volume as shown in table (2).

Table (2): Formulas for estimation of butt log volume of Calibrain pine at 6 meter length.

\begin{tabular}{|c|c|l|}
\hline No. & Name & \multicolumn{1}{|c|}{ Formula } \\
\hline 1 & Smalian's & $\mathrm{V}=((\mathrm{B}+\mathrm{S}) / 2) \mathrm{L}$ \\
\hline 2 & Huber's & $\mathrm{V}=\mathrm{M} \mathrm{L}$ \\
\hline 3 & Newton's & $\mathrm{V}=((\mathrm{B}+4 \mathrm{M}+\mathrm{S}) / 6) \mathrm{L}$ \\
\hline 4 & Hosfeld's & $\mathrm{V}=((3 \mathrm{G}+\mathrm{S}) / 4) \mathrm{L}$ \\
\hline 5 & Bruce's & $\mathrm{V}=(0.25 \mathrm{~B}+0.75 \mathrm{~S}) \mathrm{L}$ \\
\hline 6 & Sorenson's & $\mathrm{V}=(\hat{S}+0.05 \mathrm{~L})^{2} \mathrm{~L}$ \\
\hline 7 & Centroid & $\mathrm{V}=\mathrm{SL}+(1 / 2) \mathrm{b}_{1} \mathrm{~L}^{2}+(1 / 3) \mathrm{b}_{2} \mathrm{~L}^{3}$ \\
\hline
\end{tabular}

Also descriptive statistics of butt log volume at 6-m. above stump of Calibrain pine for each equation of the sampled trees are given in Table (3). 
Table (3): Descriptive statistics for seven formulas of butt log volume at 6 meter above stump of Calibrain pine.

\begin{tabular}{|c|c|c|c|c|}
\hline Formula & Maximum & Mean & Minimum & Variance \\
\hline Control & 0.549600 & 0.174200 & 0.061100 & 0.009700 \\
\hline Smalian's & 0.593900 & 0.199800 & 0.071600 & 0.011100 \\
\hline Huber's & 0.500815 & 0.155040 & 0.047124 & 0.008540 \\
\hline Newton's & 0.531838 & 0.169957 & 0.058208 & 0.009271 \\
\hline Hossfeld's & 0.594686 & 0.196073 & 0.071981 & 0.010929 \\
\hline Bruce's & 0.486984 & 0.137071 & 0.041692 & 0.007096 \\
\hline Sorenson's & 0.819435 & 0.332533 & 0.136188 & 0.022479 \\
\hline Centroid & 0.586988 & 0.172896 & 0.059731 & 0.009750 \\
\hline
\end{tabular}

The values of mean absolute percent errors (MAPE), bias and test statistics (ttest) for all the different methods used for butt log volume estimations, for the pine species, are given in Table (4). The absolute percent errors of the mean volume of Sorenson Formula (60.8512) is higher than others formula, therefore, it's not appropriate formula for estimating first $\log$ of tree (butt $\log$ ) at 6 meter length above the stump. This formula is appropriate to use when the shape of log equal to cone, therefore Sorenson Formula used to estimate volume of the tip tree approaches a cone or paraboloid in form. Centroid method and Newton formula give lower MAPE than others formula $(0.7694,2.4561)$ respectively. These two methods seem to be the most efficient for the bole volume prediction. Besides the MAPE for Huber, Hossfeld, Smalian and Bruce formulas are given higher values than Centroid method and Newton formula $(11.0175,12.5325,14.6665$ and 21.3307$)$ respectively.

Table (4): The mean Absolute Percent Error, Bias and T- test for all different methods used for butt Log Volume estimations of Calibrain pine (Pinus brutia Ten.)

\begin{tabular}{|c|c|c|c|c|c|}
\hline No & Formula & MAPE & Bias & T- test & P-value \\
\hline 1 & Control & & & & \\
\hline 2 & Smalian's & 14.6665 & 0.0256 & -2.1733 & 0.0305 \\
\hline 3 & Huber's & 11.0175 & -0.0192 & 2.3417 & 0.0199 \\
\hline 4 & Newton's & 2.4561 & -0.0043 & 0.3807 & 0.7037 \\
\hline 5 & Hosfeld's & 12.5325 & 0.0218 & -2.4628 & 0.0144 \\
\hline 6 & Bruce's & 21.3307 & -0.0372 & 3.5141 & 0.0005 \\
\hline 7 & Sorenson's & 60.8512 & 0.1583 & -10.8105 & 0.0000 \\
\hline 8 & Centroid & 0.7694 & -0.0013 & 0.1178 & 0.9063 \\
\hline
\end{tabular}

(1) Bias (\%): (+) indicates an underestimation, (-) indicates an overestimation. All other variables as previously defined. 
A t-test may also be used to test a specific hypothesis about the difference between the means of the populations from which the two samples come. In this case, the test has been constructed to determine whether the difference between the two means equals 0.0 versus the alternative hypothesis that the difference does not equal 0.0. Since the computed P-value is less than 0.05 , we can reject the null hypothesis in favor of the alternative hypothesis Fay, MP; Proschan, MA. (2010).

According to the t-test (two tailed t-test at alpha $=0.05$ ) of the Centroid method and Newton formulas of the butt log volumes were not significant for Pinus brutia Ten. and less than those derived from Smalian, Huber, Hossfeld, Bruce and Sorenson formulas. All these statistical results indicate that the Centroid method is a useful alternative to other standard formulas. Thus, this study reinforces the notion that the Centroid of a butt log defines a position of special significance for estimating its volume. Studies have shown that the Centroid method is the most accurate and Sorenson Formula is the least accurate.

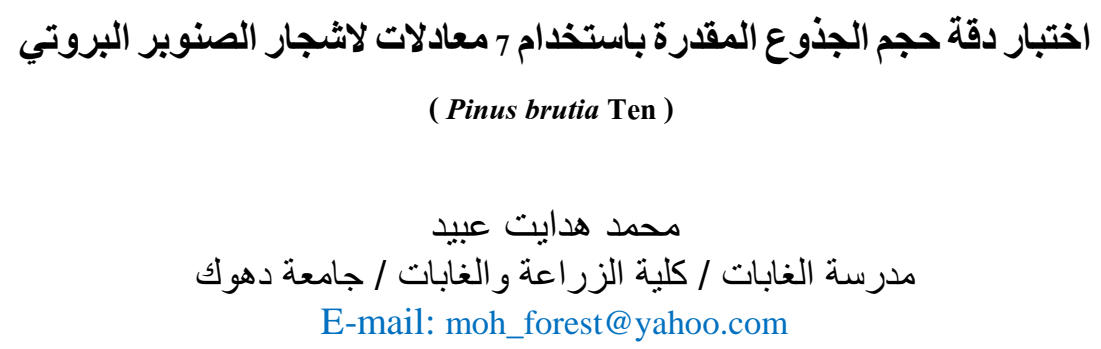

\section{REFERENCES}

Avery, T.E. and H.E. Burkhart. (2002). Forest Measurements. 5th ed. McGraw Hill,New York. 456 p.

Bruce, D. (1982). Butt log volume estimators. Journal of Forest Sciences. 28:489-503.

Fay, MP; Proschan, MA. (2010). "Wilcoxon-Mann-Whitney or t-test? On assumptions for hypothesis tests and multiple interpretations of decision rules. Statistics Surveys 4: 1-39

Husch B, Beers TW, Kershaw JA. (2003). Forest Mensuration, 4th edn. Wiley, New Jersey 
Ozçelik R, Maria J Diamantopoulou, John R Brooks and Harry V Wiant Jr (2010). Estimating tree bole volume using artificial neural network models for four species in Turkey. Journal of Environment Management. 91(3), 742-753.

Patterson, D. W., H. V. Wiant, and G. B. Wood. (1993). Comparison of the Centroid method and taper systems for estimating tree volumes. Journal of Applied Forestry, $10(1):$ 8-9.

Rayer, S. (2007). Population Forecast Accuracy: Does the Choice of Summary Measure of Error Matter?" Population Research and Policy Review. 26 (2): 163-184.

West, P. W. (2009). Tree and Forest Measurement. (Second edition). Springer-Verlag, Berlin, Australia. 191 pp.

Wiant, H. V., G. B. Wood, and G. M. Furnival. (1992). Estimating log volume using the centroid position. Journal of Forest Science, 38 (1): 187-191.

Wiant, H.V., Jr., D.W. Patterson, C.C. Hassler, G.B. Wood, and J.C. Rennie. (1996). Comparison of formulas for estimating volumes of butt logs of Appalachian hardwoods. Journal of Applied Forestry 13(1): 5-7.

Yavuz. H. (1999). Comparison of the Centroid method and four standard formulas for estimating log volumes. Tr. Journal of Agriculture and Forestry 23:597-602. 
Mesopotamia J. of Agric.

Vol. (45) No. (3) 2017
ISSN: 2224 - 9796 (Online)

ISSN: 1815 - 316 X (Print)

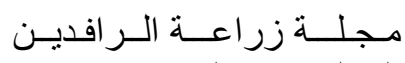

المجلد (45) العدد (3) 2017 